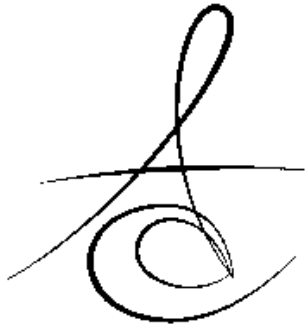

\section{ENDODONTİK ENFEKSİYONLARDA MİKROBİOLOJİK GENETİK TANI} YÖNTEMLERİNİN ROLÜ

\section{ROLE OF MOLECULAR MICROBIOLOGICAL TECHNIQUES IN ENDODONTIC INFECTIONS}

\author{
Uzm. Dt. Mehmet Selçuk ÖZBEK*
}

Makale Kodu/Article code: 1979

Makale Gönderilme tarihi: 25.11.2014

Kabul Tarihi: 18.05.2015

\section{ÖZET}

Endodontik enfeksiyonlar anaerobik türlerin baskın olarak bulunduğu polimikrobiyal enfeksiyonlardır. Geleneksel olarak endodontik mikroflora, mikrobiyolojik kültür yöntemleri kullanılarak araştırımıştır. Ancak bu yöntemlerin mikrobiyolojik tanıda kısıtlı kalabildiği belirtilmektedir. Son yıllarda kültürden bağımsız moleküler genetik yöntemlerin kullanılması ile hem kültür temelli çalışmaların sonuçları desteklenmiş, hem de bu sonuçlara önemli derecede ilave bilgiler eklemiştir. Moleküler genetik çalışmaların sonuçları endodontik enfeksiyonlardaki bakteriyel çeşitlilik hakkındaki bilgilerin artmasını sağlamıştır. Bu derleme endodontik enfeksiyonlarda moleküler genetik yöntemlerin rolü hakkında bilgi sunmaktadır.

Anahtar kelimeler: Endodontik Enfeksiyonlar, Moleküler Mikrobiyolojik Yöntemler

\section{GİRIŞ}

Endodontik enfeksiyonlar, pulpa ve periapikal dokuların enfeksiyonu olarak tanımlanırlar. ${ }^{1} \quad \mathrm{Bu}$ enfeksiyonlar zorunlu anaerop bakterilerin çoğunlukta olduğu polimikrobiyal özellikte enfeksiyonlardır. ${ }^{2}$ Oral kavite, nazofarinks ve gastrointestinal bölgelerdeki herhangi bir mikrororganizma kök kanalına yerleşip çoğalarak enfeksiyona yol açabilir. Enfekte kök kanalına girebilen ve hastalık yapabilen mikroorganizmaların büyük çoğunluğu bakterilerdir. ${ }^{2,3}$

İnsan vücudunun farklı bölgelerindeki bakteriyel çeşitliliği araştırmak için yapılan çalışmalar farklı bakteri gruplarının \%50-80'ninin, endodontik floradaki bakterilerin ise yaklaşık \%40-55'inin kültüre edilemedi-

\section{ABSTRACT}

Endodontic infections are polymicrobial infections dominated by anaerobic species. The endodontic microflora has been traditionally investigated by microbiologic culture methods, which have been demonstrated to have several limitations when it comes to microbiological diagnosis. More recently, not only have findings from culture-based methods been confirmed, but they have also been significantly supplemented with those from culture-independent molecular genetic techniques. The results from molecular genetic studies impact remarkably on the knowledge of bacterial diversity in endodontic infections. Present review focuses on the role of molecular genetic techniques in endodontic infections.

Keywords: Endodontic Infections, Molecular Mikrobiologic Techniques

ğini rapor etmektedir. ${ }^{4-7}$ Kök kanal enfeksiyonlarındaki kültüre edilemeyen bakterilerin, hastalığın başlangıcın$\mathrm{da}$, ilerlemesinde veya her ikisinde de potansiyel bir rol oynama intimali vardır. ${ }^{1}$

Kök kanal tedavilerinin başarı oranının artmasına yönelik yeni ve etkili stratejilerin geliştirilebilmesi kök kanal sistemindeki patojenik etkenlerin iyi anlaşılmasına bağlıdır. ${ }^{8}$ Endodontik enfeksiyonlarda bakteriyel florayı araştırmak için yapılan çalışmalarda çoğunlukla kültür temelli tanı yöntemleri kullanılmıştır. ${ }^{1-3}$ Kültür yöntemlerinin en büyük avantajı, tek bir örnek içinde bulunan ve çeşitlilik gösteren mikrobiyal türlerin tanımlanabilmesine imkân sağlamasıdır. Ayrıca kültür işlemleri, izolasyonların antimikrobiyal duyarlılıkların belirlemeye ve bu izolasyonların fizyolo-

*Endodontist Dt. Ph.D Ağız Diş Sağlığı Hastanesi, Eskişehir, Türkiye

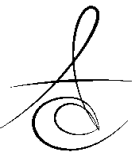


jilerini, biyokimyasal ve genetik özellikleri ile patolojilerini de çalışmaya olanak vermektedir., ${ }^{2,7,8}$ Ancak bu yöntemlerin bazı bakteri gruplarını tanımlamada yetersiz kalabilmeleri araştırmacıları ileri tanı yöntemleri kullanmaya yönlendirmiştir. ${ }^{7,8}$

\section{Moleküler Esas/ı Yöntemler}

Moleküler yöntemlerin hücre canlılığını temel almadan bakteriyel tanı yapabilmeleri, bu yöntemleri, özellikle zorunlu anaerobik enfeksiyonlarda yapılan çalışmalarda, avantajlı hale getirmektedir. ${ }^{9}$ Moleküler yöntemlerin çoğu ribozomal RNA genini (rDNA'yı) kullanarak, kültüre intiyaç duyulmadan, mikroorganizmaların tanımlanmasını yapabilmektedir. 16S rDNA geni, moleküler yaklaşımlarda, bakteriyel tanıda en sık kullanılan hedef bölgedir. Bu gen, korunmuş bölgeler (bakterilerin hepsinde aynı olan bölgeler) ve değişken bölgelerden (bir bakteriden diğerine değişiklik gösteren bölgeler) oluşur. 16S rDNA geninde bulunan değişken bölgeler, spesifik tanımlamada kullanılan bölgelerdir. ${ }^{1,2,7}$

Diğer tanı yöntemlerinde olduğu gibi moleküler esaslı yöntemlerinde kendilerine özgü avantaj ve dezavantajları vardır. ${ }^{2} \mathrm{Bu}$ avantajlar arasında öne çıkanlar:

$\checkmark$ Hem kültüre edilebilen hem de kültüre edilemeyen bakteri türlerini tespit edebilmeleri,

$\checkmark$ Özgüllüklerinin yüksek olması ve fenotipik olarak kesin olmayan davranış sergileyen mikrobiyal türlerin tanımlarını doğru bir şekilde yapabilmeleri,

$\checkmark$ Mikrobiyal türleri, kültüre ihtiyaç duymadan direk olarak tespit edebilmeleri,

$\checkmark$ Duyarlılıklarının diğer tanı yöntemlerine göre daha yüksek olması,

$\checkmark$ Hızlı olmaları ve az zaman almaları,

$\checkmark$ Örneklerin alınması ve taşınması esnasında anaeropik koşulların sağlanmasına ihtiyaç duyulmaması.

$\checkmark$ Antimikrobiyal tedavi süresince kullanılabilir olmaları sayılabilir. ${ }^{2,7}$

Moleküler yöntemler içerisinde mikrobiyal tanıda en sık kullanılan yöntem polimeraz zincir reaksiyonu (PCR) ve onun varyasyonlarıdır. ${ }^{2,10,11}$ PCR yöntemi, bir gen veya DNA bölgesinin, bu bölgeye bağlanan oligonükleotid primerler (öncüler) aracılığıyla bir dizi replikasyon döngüsü geçirerek çoğaltılması esasına dayanır. ${ }^{12}$ PCR ile istenilen genlerin ya da DNA dizilerinin jenerasyonlara bağı replikasyonu, hızlandırılmış bir şekilde gerçekleştirilir. ${ }^{13}$
PCR ilk defa 1985 yılında Saiki ve arkadaşları tarafından, orak hücreli anemi hastalığının teşhisi amacıyla geliştirilmiş ve kullanılmıştır. ${ }^{14}$

\section{PCR Çeşitleri}

Yaygın olarak kullanılan PCR çeşitleri; Klasik (single) PCR, yuvalanmış (nested) PCR, geri (revers) transkripsiyon PCR, çoklu (multipleks) PCR ve gerçek zamanlı (real-time) PCR'dır. ${ }^{7,11}$

\section{Klasik PCR}

Hedef DNA dizisinin her iki ucuna özgü spesifik primerler kullanılarak, termostabil DNA polimeraz enzimi yardımıyla yapılan PCR yöntemidir. ${ }^{12,13}$ Diğer PCR yöntemlerine kıyasla daha kolay uygulanabilse de çapraz kontaminasyon riski taşıması, amplifikasyon (PCR ile DNA parçasının çoğaltılması) sonrası analiz gerektirmesi ve fazla zaman alması dezavantajlarıdır. ${ }^{11-13}$

\section{Yuvalanmış $P C R$}

$\mathrm{Bu}$ yöntemde PCR verimini artırmak için nested yani birbiri için gömülmüş primer setleri kullanılır. ${ }^{15}$ İlk amplifikasyonda elde edilen ürün, ikinci PCR için kalıp olarak kullanılır. ${ }^{13}$ Böylece DNA amplifikasyon hassasiyeti ve özgünlüğü önemli ölçüde arttırılabilir. Ancak kontaminasyon riski yüksek bir yöntemdir. 2,7,12,13,15

\section{Geri transkripsiyon PCR}

Spesifik proteinleri kodlayan messenger RNA'yı tespit edebilen bu yöntem mikroorganizmaların fenotipleri hakkında önemli ipuçları verir. İki aşamalı olup RNA'dan complementer DNA (cDNA) sentezi (geri transkripsiyon) ve tamamlayıcl CDNA'nın da standart PCR yoluyla çoğaltılması aşamalarını kapsar. ${ }^{2,13}$

\section{Çoklu PCR}

Standart bir PCR reaksiyonunda özel bir sekansı çoğaltmak için tek primer çifti kullanılırken, çoğul PCR'da bir çok sekansı eş zamanlı çoğaltmak amacıyla birden fazla primer çifti kullanılır. ${ }^{16}$ Çoklu PCR analizleri, PCR sürelerini ve maliyetlerini azaltmak amacıyla kullanılmaktadır. ${ }^{2,7,13}$

\section{Gerçek zamanlı PCR}

Son yıllarda PCR reaksiyonlarında sıcaklık döngüleri sağlamak için kullanılan cihazların hassas ölçüm aletleriyle birleştirilmesi, gerçek zamanlı PCR olarak adlandırılan yeni bir yöntemin gelişmesine neden olmuştur. ${ }^{12,13} \mathrm{Bu}$ yöntemde ürünlerin analizi reaksiyon sırasında yapılmaktadır. Bu nedenle, agaroz jel elektroforezi, DNA bantlarının mor ötesi ışık altında görüntülenmesi gibi işlemlerin uygulanmasına gerek 
kalmamaktadır. ${ }^{15-18}$ SYBR- Green, Molecular Beacon ve TaqMan sıklıkla kullanılan gerçek zamanlı PCR yaklaşımlarıdır. ${ }^{17,18}$

PCR yöntemlerinin dezavantajlarından bazıları şunlardır:

- PCR yöntemlerinin, real-time PCR haricinde, hedef mikroorganizmanın tanısını niteliksel olarak yapabilmeleri ve örnek içindeki mikroorganizma miktarını belirleyememeleri.

- PCR yöntemlerinin çoğunun aynı anda sadece bir türü veya multipleks $\mathrm{PCR}^{\prime}$ da olduğu gibi çok az sayıda farklı türleri tespit edebilmeleri.

- Klinik örneklerde bulunabilen enzim inhibitörlerinin aynı zamanda PCR inhibitörü olarak da etki edip amplifikasyon reaksiyonunda başarısızlığa yol açabilmesi.

- Kontamine olan DNA' nın amplifikasyonu sonucu yanlış pozitif sonuçların ortaya çıkma olasılığının bulunmasıdır. ${ }^{2,7}$

Anaerobik Gram-negatif türler, Gram-pozitif anaeroplar, fakültatif ve mikroaerofilik streptokoklar endodontik enfeksiyonlardan sıklıkla izole edilen bakterilerdir. ${ }^{19-21}$ Prevotella ve Porphyromonas grubunun bazı türleri, peptostreptokoklar, peptokoklar, Fusobacterium spp., Eubacterium spp. ve Actinomyces spp. grubuna katılan bazı bakterilerin, klinik semptomlar ile ilişkilerinin bulunabileceğini bildiren farklı araştırmalar bulunmaktadır. ${ }^{22-25}$

Bazı bakteri türlerinin, beslenme ve çevresel faktörlere göstermiş oldukları aşırı duyarlıık, bu bakterileri tanımlamak amacıyla kullanılan çeşitli biyokimyasal testlerin birbirinden farklı sonuçlar vermesine ve farklı yorumlamaya bağlı olarak yanlış bakteri tanımlamalarına neden olabilmektedir. ${ }^{26,27}$ Bunun sonucunda ise bazı bakteri türleri veya suşları mevcut değerlerinden az bulunurken, bazı bakteri türlerinin ise tanımlanması yapılamamıştır. ${ }^{1,2,7,8,26,27}$ Araştırmalar, endodontik enfeksiyonlarda kültür yöntemleri negatif sonuç verdiğinde moleküler yöntemlerin bakteri varlığını tespit edebildiğini göstermektedir. 1,2,7-9,26

Kök kanalından ve periapikal lezyonlardan alınan mikrobiyal örneklerin analizinde kullanılan moleküler yöntemler arasında PCR, moleküler klonlama, DNA probları, DNA dizi analizleri, nükleik asit melezleme (hibridizasyon) yöntemleri, denaturing gradient jel elektroforez analizleri (DGGE) yer almaktadır. ${ }^{27-34}$

Moleküler yöntemler kullanılarak yapılan araştırmalar, apikal periodontitis ve farklı bakteri türleri arasındaki ilişkiyi hem güçlendirmiş hem de endodontik patojen olabileceği düşünülen yeni türlerin belirlenmesini sağlamışlardır. ${ }^{35}$ Kültüre edilebilmesi güç olan veya henüz kültüre edilemeyen bakterilerin endodontik enfeksiyonlarda moleküler yöntemler kullanılarak tespiti, kök kanalı ve periapikal lezyonlardaki bakteriyel çeşitliliği önemli derecede artırmıştır. ${ }^{1,2}$

Endodontik enfeksiyonların 400'den fazla farklı bakteri türü barındırdığı düşünülmektedir. Bu farklı türlerin yaklaşık \% 45'i moleküler biyoloji çalışmalarında \% 32'si ise kültür temelli çalışmalardan rapor edilmiştir. $^{2}$ Periodontal patojen olarak bilinen Tannerelia forsythia (önceden kullanılan adı Bacteroides forsythus veya Tannerella forsythensis ) ilk defa endodontik enfeksiyonlardan klasik PCR yöntemi ile bulunmuştur. ${ }^{28}$ Kültürden bağımsız yapılan farklı moleküler esaslı çalışmalar (yuvalanmış PCR, hibridizasyon gibi) bu patojenin apseleri de kapsayan endodontik enfeksiyonlarda önemli bir patojen olduğunu göstermiştir. ${ }^{36-38}$

Gram-negatif zorunlu anaerobik bakterilerden olan Dialister türleri de moleküler yöntemler sayesinde bulunan diğer bir bakteri türüdür. Bu türde yer alan $D$. pneumosintes ve $D$. invisus semptomatik ve asemptomatik endodontik enfeksiyonlardan sıklıkla tespit edilen türlerdir. ${ }^{39,40}$ Endodontik mikroflorada sıklıkla bulunan Fusobacterium nucleatum'un aynı enfekte kanalda farklı klonal tiplerinin izole edilebileceği PCR esaslı moleküler yöntemler aracılığıyla yapılabilmiştir. ${ }^{41}$

Uzun yıllar boyunca spiroketler, endodontik enfeksiyonlardan alınan örneklerde mikroskop kulanılarak gözlemlenebilmiş olsalar da tür seviyesinde tanımlanmaları yapılamamıştır. ${ }^{42,43}$ Yapılan farklı moleküler çalışmalar endodontik enfeksiyonlarda bulunan spiroketlerin treponema türüne ait olduğunu göstermiştir. Treponema denticola ve Treponema socranskii endodontik kaynaklı enfeksiyonlarda moleküler yöntemler ile sıklıkla bulunan türlerdir. ${ }^{44}$

Zorunlu anaerobik bakteriler arasında yer alan Filifactor alocis kök kanallarından alınan örneklerde kültür yöntemleri ile çok nadir izole edilmiştir. ${ }^{45}$ Oysa yuvalanmış PCR kullanarak yapılan bir çalışmada bu tür, endodontik enfeksiyonların yaklaşık yarısında tespit edilmiştir. ${ }^{46}$ Porphyromonas endodontalis, $P$. gingivalis, Fusobacterium nucleatum, Pseudoramibacter alactolyticus, Propionibacterium propionicum, Actinomyces spp., Slackia exigua ve Mogibacterium 
timidum moleküler tanı yöntemleri kullanılarak endodontik enfeksiyonlardan daha yüksek oranda bulunan türler arasında yer alırlar. ${ }^{2,7,44}$ Prevotella tannerrae, Fusobacterium periodonticum, Olsenella spp., Eubacterium infirmum ve Centipeda periodontii ise endodontik enfeksiyonlardan moleküler esaslı yöntemler kullanılarak bulunan aday endodontik patojenler arasında yer alırlar. 2,28,44,47-50

Periapikal granülomlarda farklı virüslerin varlığı gösterilmiş ${ }^{51}$ olsa da apikal periodontitisin oluşumu ve ilerlemesindeki rolleri hakkındaki bilgiler çok sınırlıydı. ${ }^{3}$ Son yillarda Parra ve Slots ${ }^{52}$ ile Contreras ve Slots ${ }^{53}$, PCR kullanarak yaptıkları çalışmalarda periodontal ceplerde çeşitli viral transkripsiyonların varlığını göstermişlerdir. Bu çalışmaların sonuçlarını takiben Sabeti ve arkadaşları ${ }^{55,56}$ marjinal periodontitis ile benzer olarak apikal periodontitisin patogenezinde herpes viral enfeksiyonun rol oynayabileceğini belirtmişlerdir. Slots ve arkadaşları ${ }^{56}$ da farklı herpes virüslerin apikal periodontitisin patogenezine dâhil olabileceği fikrini savunmuştur. Bu çalışmaların ışı̆ında yapılan pek çok moleküler çalışmada farklı virüsler ve endodontik kaynaklı periapikal lezyonlar ile ilgili değerli bilgilere ulaşılmıştır. ${ }^{10,57-59}$

\section{SONUÇ}

Moleküler genetik yöntemlerin endodontik enfeksiyonlardaki bakteriyel ve viral florayı araştırmada kullanılabilmesi bize bu enfeksiyonları daha iyi anlamamıza yardımc olmaktadır. Yakın gelecekte kullanılacak yeni moleküler esaslı tanı yöntemleri yeni patojenleri tanımamıza dolayısıyla etkene spesifik antibakteriyel tedavi yaklaşımları ile tedavi başarılarının daha da artmasına imkân sağlayacaktır.

\section{KAYNAKLAR}

1. Spratt DA. Significance of Bacterial Identification by Molecular Biology Methods. Endod Top 2004;9:5-14.

2. Baumgartner JC, Hutter JW, Siqueira JF, Jr. Pathways of the Pulp. 9 ed. St. Louis; Mosby: 2006. p. 580-607.

3. Chow AW. Principles and Practice of Infectious Diseases. Pennsylvania; Churchill Livingstone: 2000. p. 689-702.

4. Eckburg PB, Bik EM, Bernstein CN, Purdom E, Dethlefsen L, Sargent M, Gill SR, Nelson KE,
Relman DA. Diversity of the Human Intestinal Microbial Flora. Science 2005;308:1635-8.

5. Kumar PS, Griffen AL, Moeschberger ML, Leys EJ. Identification of Candidate Periodontal Pathogens and Beneficial Species by Quantitative 16S Clonal Analysis. J Clin Microbiol 2005;43:3944-55.

6. Paster BJ1, Boches SK, Galvin JL, Ericson RE, Lau CN, Levanos VA, Sahasrabudhe A, Dewhirst FE. Bacterial Diversity in Human Subgingival Plaque. J Bacteriol 200;183:3770-83.

7. Siqueira JF Jr, Rôças IN. Exploiting Molecular Methods to Explore Endodontic Infections: Part 1Current Molecular Technologies for Microbiological Diagnosis. J Endod 2005;31:411-23.

8. Sakamoto M, Rôças IN, Siqueira JF Jr, Benno Y. Molecular Analysis of Bacteria in Asymptomatic and Symptomatic Endodontic Infections. Oral Microbiol Immunol 2006;21:112-22.

9. Rolph $H J$, Lennon A, Riggio MP, Saunders WP, MacKenzie D, Coldero L, Bagg J. Molecular Identification of Microorganisms from Endodontic Infections. J Clin Microbiol 2001;39:3282-9.

10. Ozbek SM, Ozbek A, Yavuz SM. Detection of Human Cytomegalovirus and Epstein-Barr Virus in Symptomatic and Asymptomatic Apical Periodontitis Lesions by Real-Time PCR. Med Oral Patol Oral Cir Bucal 2013;18:811-6.

11. Siqueira JF Jr, Rôças IN. PCR Methodology as a Valuable Tool for Identification of Endodontic Pathogens. J Dent 2003;31:333-9.

12. Ulusoy AÖİ, Görgül G. Polimeraz Zincir Reaksiyonu (PCR) ve Endodontik Mikrobiyoloji. Atatürk Üniv Diş Hek Fak Derg 2006;16:61-5.

13. Arı Ş. Moleküler Biyolojide Kullanılan Yöntemler. İstanbul; Nobel Tıp Kitap Evleri: 2004. p. 101-20.

14. Saiki RK, Scharf S, Faloona F, Mullis KB, Horn GT, Erlich HA, Arnheim N. Enzymatic Application of Beta-Globin Genomic Sequences and Restriction Site Analysis for Diagnosis of Sickle Cell Anemia. Science 1985;230:1350-4.

15. Niederhauser C, Höfelein C, Wegmüller B, Lüthy J, Candrian U. Reliability PCR Decontamination Systems. PCR Methods and Applications 1994;4:117-23.

16. Atlas RM, Bej AK. Methods for General and Molecular Bacteriology. Washington, D.C; American Society for Microbiology: 1994. p. 41835. 
17. Cashion Ak, Driscoll $\mathrm{Cj}$, Sabek O. Emerging Genetic Technologies in Clinical and Research Settings. Biol Res For Nurs 2004;5:159-67.

18. Mackay IM. Real Time PCR in the Microbiology Laboratory. Clin Microbiol Infect 2004;10:190212.

19. Sundqvist G. Associations Between Microbial Species in Dental Root Canal Infections. Oral Microbiol Immunol 1992;7:257-62.

20. Lana MA, Ribeiro-Sobrinho AP, Stehling $R$, Garcia GD, Silva BK, Hamdan JS, Nicoli JR, Carvalho MA, Farias Lde M. Microorganisms Isolated from Root Canals Presenting Necrotic Pulp and their Drug Susceptibility In Vitro. Oral Microbiol Immunol 2001;16:100-5.

21. Peters LB, Wesselink PR, Van Winkelhoff AJ. Combinations of Bacterial Species in Endodontic Infections. Int Endod J 2002;35:698-702.

22. Haapasalo M, Ranta H, Ranta K, Shah H. BlackPigmented Bacteroides Spp. in Human Apical Periodontitis. Infect Immun 1986;53:149-53.

23. Yoshida M, Fukushima H, Yamamoto K, Ogawa K, Toda T, Hirosuke S. Correlation Between Clinical Symptoms and Microorganisms isolated from Root Canals of Teeth with Periapical Pathosis. J Endod 1987;13:24-8.

24. Hashioka K, Yamasaki M, Nakane A, Horiba N, Nakamura $\mathrm{H}$. The Relationship Between Clinical Symptoms and Anaeropic Bacteria from Infected Root Canals. J Endod 1992;18:558-61.

25. Gomes BPFA, Lilley JD, Drucker DB. Clinical Significance of Dental Root Canal Microflora. J Dent 1996;24:47-55.

26. Drancourt M, Bollet C, Carlioz A, Martelin R, Gayral JP, Raoult D. 16S Ribosomal DNA Sequence Analysis of a Large Collection of Environmental and Clinical Unidentifiable Bacterial Isolates. J Clin Microbiol 2000;38:3623-30.

27. Santala AM, Sarkonen N, Hall V, Carlson P, Jousimies-Somer $\mathrm{H}$, Könönen $E$. Evaluation of Four Commercial Test Systems for Identification of Actinomyces and Some Closely Related Species. J Clin Microbiol 2004;42:418-20.

28. Conrads G, Gharbia SE, Gulabivala K, Lampert F, Shah HN. The Use of a $16 \mathrm{~S}$ rDNA Directed PCR for the Detection of Endodontopathogenic Bacteria. J Endod 1997;23:433-38.
29. Gharbia SE, Haapasalo M, Shah HN, Kotiranta A, Lounatmaa $K$, Pearce MA, Devine DA. Characterization of Prevotella Intermedia and Prevotella Nigrescens Isolated from Periodontic and Endodontic Infections. J Periodontol 1994;65:56-61.

30. Baumgartner JC, Bae KS, Xia T, Whitt J, David LL. Sodium Dodecyl Sulfate-Polyacrylamide Gel Electrophoresis and Polymerase Chain Reaction for Differentiation of Prevotella Intermedia and Prevotella Nigrescens. J Endod 1999;25:324-8.

31. Dymock D, Weightman $A j$, Scully $C$, Wade Wg. Molecular Analysis of Microflora Associated with Dentoalveolar Abscesses. J Clin Microbiol 1996;34:537-42.

32. Sunde PT, Tronstad L, Eribe ER, Lind PO, Olsen I. Assesment of Periradicular Microbiota by DNADNA Hybridization. Endod Dent Traumatol 2000;16:191-6.

33. Siqueira JF Jr, Rôças IN, Rosado AS. Application of Denaturing Gradient $\mathrm{Gel}$ Electrophoresis (DGGE) to the Analysis of Endodontic İnfections. J Endod 2005;31:775-82.

34. Oliveira JC, Siqueira JF Jr, Rôças IN, Baumgartner JC, Xia T, Peixoto RS, Rosado AS. Bacterial Community Profiles of Endodontic Abscesses from Brazilian and USA Subjects as Compared by Denaturing Gradient Gel Electrophoresis Analysis. Oral Microbiol Immunol 2007;22:14-8.

35. Siqueira JF Jr, Rôças IN. Exploiting Molecular Methods to Explore Endodontic Infections: Part 2Redefining the Endodontic Microbiota. J Endod 2005;31:488-98.

36. Siqueira JF Jr, Rôças IN. Bacteroides Forsythus in Primary Endodontic Infections as Detected by Nested PCR. J Endod 2003;29:390-3.

37. Siqueira JF Jr, Rôças IN, Souto R, Uzeda $M$, Colombo AP. Microbiological Evaluation of Acute Periradicular Abscesses by DNA-DNA Hybridization. Oral Surg Oral Med Oral Patbol Oral Radiol Endod 2001;92:451-7.

38. Vianna ME, Horz HP, Gomes BP, Conrads G. Microarrays Complement Culture Methods for Identification of Bacteria in Endodontic Infections. Oral Microbiol Immunol 2005;20:253-8.

39. Rôças IN, Siqueira JF Jr. Identification of Dialister Pneumosintes in Acute Periradicular Abscesses of Humans by Nested PCR. Anaerobe 2002;8:75-8.

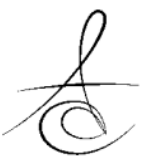


40. Saito D, Leonardo Rde T, Rodrigues JL, Tsai SM, Höfling JF, Gonçalves RB. Identification of Bacteria in Endodontic İnfections by Sequence Analysis of $16 \mathrm{~S}$ rDNA Clone Libraries. J Med Microbiol 2006;55:101-7.

41. Moraes SR, Siqueira JF Jr, Rôças IN, Ferreira MC, Domingues RM. Clonality of Fusobacterium Nucleatum in Root Canal Infections. Oral Microbiol Immunol 2002;17:394-6.

42. Trope M, Tronstad L, Rosenberg ES, Listgarten M. Darkfield Microscopy as a Diagnostic Aid in Differentiating Exudates from Endodontic and Periodontal Abscesses. J Endod 1988;14:35-8.

43. Nair PNR. Light and Electron Microscopic Studies of Root Canal Flora and Periapical Lesions. J Endod 1987; 13:29-39.

44. Baumgartner JC, Siqueira JF Jr, Sedgley CM, Kıshen A. Ingle's Endodontics. 6 ed. Hamiliton, CA; BC Decker, Inc: 2008. p. 221-308.

45. Sundqvist GK. Associations between Microbial Species in Dental Root Canal Infections. Oral Microbiol Immunol 1992;7:257-62.

46. Siqueira JF Jr, Rôças IN. Detection of Filifactor Alocis in Endodontic Infections associated with Different Forms of Periradicular Diseases. Oral Microbiol Lmmunol 2003;18:263-5.

47. Xia T, Baumgartner JC, David LL. Isolation and Identification of Prevotella Tannerae from Endodontic Infections. Oral Microbiol Immunol 2000;15:273-5.

48. Siqueira JF Jr, Rôças IN, Souto R, Uzeda M, Colombo AP. Microbiologicial Evaluation of Acute Periradicular Abscesses by DNA-DNA Hybridization. Oral Surg Oral Med Oral Pathol Oral Radiol Endod 2001;92:451-7.

49. Fouad AF, Kum KY, Clawson ML, Barry J, Abenoja C, Zhu Q, Caimano M, Radolf JD. Molecular Characterization of The Presence of Eubacterium Spp. and Streptococcus Spp. in Endodontic Infections. Oral Microbiol Immunol 2003;18:24955.

50. Siqueira JF Jr, Rôças IN. Nested PCR Detection of Centipeda Periodontii in Primary Endodontic Infections. J Endod 2004;30:135-37.

51. Shindell E. Studies on The Possible Presence of A Virus in Subacute and Chronic Periapical Granulomas. Oral Surg Oral Med Oral Pathol 1962;15:1382-4.
52. Parra B, Slots J. Detection of Human Viruses in Periodontal Pockets Using Polymerase Chain Reaction. Oral Microbiol Immunol 1996;11:28993.

53. Contreras A, Slots J. Mammalian Viruses in Human Periodontitis. Oral Microbiol Immunol 1996;11:381-6.

54. Sabeti M, Simon JH, Slots J. Cytomegalovirus and Epstein-Barr Virus are associated with Symptomatic Periapical Pathosis. Oral Microbiol Immunol 2003;18:327-8.

55. Sabeti $M$, Valles $Y$, Nowzari $H$, Simon $J H$, Kermani-Arab V, Slots J. Cytomegalovirus and Epstein-Barr Virus DNA Transcription in Endodontic Symptomatic Lesions. Oral Microbiol Immunol 2003;18:104-8.

56. Slots J, Sabeti M, Simon JH. Herpesviruses in Periapical Pathosis: An Etiopathogenic Relationship? Oral Surg Oral Med Oral Pathol Oral Radiol Endod 2003;96:327-31.

57. Li H, Chen V, Chen Y, Baumgartner JC, Machida CA. Herpesviruses in Endodontic Pathoses: Association of Epstein-Barr Virus with Irreversible Pulpitis and Apical Periodontitis. J Endod 2009;35:23-9.

58. Hernádi K, Szalmás A, Mogyorósi R, Czompa L, Veress G, Csoma $E$, Márton I, Kónya J. Prevalence and Activity of Epstein-Barr Virus and Human Cytomegalovirus in Symptomatic and Asymptomatic Apical Periodontitis Lesions. J Endod 2010;36:1485-9.

59. Ozbek A, Ozbek SM. Detection of Herpesviruses and Human Papillomavirus in Acute Apical Abscesses by Real-Time PCR. Clin Oral Investig 2015;19:343-7.

\section{Yazışma Adresi}

Uzm. Dt. Mehmet Selçuk Özbek

Ağız ve Diş Sağlığı Hastanesi

Eskişehir, Türkiye

Fax: +90 2222293854

Tel: +90 5465476426

E-mail: selcuk233@yahoo.co 